Sandra H. Robbins ${ }^{1}$, UNIVERSITY OF WEST GEORGIA, srobbins@westga.edu

Kristen Gilbert ${ }^{1}$, AUGUSTA UNIVERSITY, krgilbert@augusta.edu

Frances Chumney, THE MARCUS BUCKINGHAM COMPANY; ADP RESEARCH INSTITUTE,

PEOPLE AND PERFORMANCE, frances.chumney@tmbc.com

Katherine B. Green, UNIVERSITY OFWEST GEORGIA, kbgreen@westga.edu

\title{
The Effects of Immersive Simulation on Targeted Collaboration Skills Among Undergraduates in Special
}

\section{Education}

\section{ABSTRACT}

The use of immersive simulation as a pedagogical tool has great potential for making a significant impact on student learning in higher education. In this study, the effect of immersive simulation was evaluated for a cohort of undergraduate special education majors. The investigation aimed to determine whether facilitating an immersive co-planning simulation would have an impact on targeted collaboration skills and whether vicarious observational learning would occur for students who observed the simulation. Pre-service teachers in special education were evaluated by their peers on their ability to demonstrate knowledge of (1) co-teaching and co-planning, (2) professional communication, and (3) supports for students with disabilities. The results indicate that they did a better job of facilitating a co-planning session after having first practiced doing so via immersive simulation during a previous class session. It was also discovered that vicarious observational learning during immersive simulation positively affected performance.

\section{KEYWORDS}

teacher preparation, special education, collaboration, immersive simulation

\section{INTRODUCTION}

In light of emerging use of practice-based teacher education (National Council for Accreditation of Teacher Education, 2010; Council for the Accreditation of Educator Preparation, 2013), personnel preparation programs are vigorously searching for innovative and meaningful learning experiences to narrow the research to practice gap (Brownell, Ross, Colón, \& McCallum, 2005; Dieker, Hynes, Hughes, \& Smith, 2008). In theory, teaching students to become professional educators can be accomplished in the higher-education classroom, but without authentic opportunities to practice highleverage skills, pre-service teachers enter their first year ill-prepared (Robbins \& Searby, 2013). Fortunately, teaching and learning in higher-education classrooms can be enhanced through the use of innovative technology, which has been shown to prepare students to navigate more adeptly in real-world situations (Peters \& Araya, 2011). Immersive simulation is one such technological enhancement. Similar to what is more commonly known as virtual reality, immersive simulations allow users to 
perceive themselves as interacting in real-life situations, thus giving them the opportunity to practice and reflect upon the use of novel skills in a risk-free environment. In both general and special education teacher preparation programs, the use of immersive simulations has been shown to be an effective way to provide students with innovative and direct learning experiences that improve targeted teaching skills (Dawson, \& Lignugaris/Kraft, 2016; Chini, Straub, \& Thomas, 2016; Vince-Garland, Vasquez, \& Pearl, 2012). Research has also demonstrated that when combined with direct experiences, vicarious observational learning is a powerful pedagogical tool (Hoover, Giambatista, \& Belkin, 2012). These findings may indicate that students who are exposed to immersive simulation, whether they are participating in the simulation or just observing others, may be more prepared to navigate real-world situations during their first years of teaching. This study aimed to explore this possibility further by examining the effect of immersive simulation on targeted skills among pre-service teachers, and determining whether vicarious observational learning would play into that equation.

As described by Gilbert (2017), immersive simulation refers to technology-enhanced role playing via the use of augmented or mixed-reality technology. The particular platform used in this study works through digital puppetry in which a simulation specialist controls an avatar's movements and responses to participants. Because there is a human in the loop, the avatars are capable of responding in real time. Prior to immersive simulation sessions with participants, professors who have designed scenarios, role-play with the simulation specialist to help calibrate appropriate responses for both wellexecuted and poorly executed interactions and skills on the participants' part. This ensures that when participants enter the immersive simulation with the avatar(s), that the simulation specialist will embody the characteristics of the person (or people) she is playing, in this case a classroom of students. As such, the simulation specialist can respond uniquely to each participant's skill level. When participants (preservice teachers, in this case) enter their classroom, there is a life-size screen projecting images of avatars in a classroom. When ready for interaction, the participants announces, "Start simulation," and the avatars begin responding to the teacher's statements and interactions as would real classroom students. This type of interaction creates a suspension of disbelief while affording an opportunity for transfer of theory to practice in a risk-free environment. This learning platform is ideal for pre-service teacher development (Straub, Dieker, Hynes, \& Hughes, 2014), and provides an avenue for teacher preparation programs to employ pedagogical tools that deliver information, consequences, and opportunities for retooling quickly.

\section{LITERATURE REVIEW}

Given a prominent shift in focus in teacher preparation programs at universities to acknowledge the value of skill development and their application prior to entering the field (National Council for Accreditation of Teacher Education, 2010; Council for the Accreditation of Educator Preparation, 2013), most programs now include both coursework and field-based components (Allsopp, DeMarie, Alvarez-McHatton, \& Doone, 2006). However, with the potential for consequences associated with the accountability era, educators are increasingly reluctant to turn over their classrooms to pre-service teachers for a semester of field-based practice. Furthermore, the rigor and quality of these field-based learning opportunities vary a great deal based on a number of hard-to-control factors, such as experience of the mentor, depth and breadth of the job-embedded learning opportunities, and resolve of the mentor and university to attend to the insularity of the field experience (Darling-Hammond, Meyerson, 
LaPointe, \& Orr, 2010). This variability highlights a need to develop and hone skills through a variety of modalities, including with innovative technologies such as immersive simulations. While there are many immersive simulation platforms, several lack a human in the loop (referred to as a simulation specialist) and therefore have a narrow range of computer-generated responses. The immersive simulation platform used in this study allows participants to interact with an avatar, played by a human actor, that is capable of displaying a range of interactions, emotions, and behaviors. As described above, the simulation specialist practices responses that would be typical of well-executed or poorly executed skills, such as providing instructions. During the simulation, participants can pause the scenario, seek guidance and feedback from peers or the professor, and repeat an interaction applying a different approach to improve their use of teaching strategies.

Learning through this medium allows for access where it might not otherwise exist, an authentic and risk-free learning environment, consistent and comprehensive learning opportunities for participants, and a greater degree of control over quality and rigor (Miller, Rambeck, \& Snyder, 2014). In fact, the use of immersive simulations was rated by an international panel of experts in business, technology, and education as having the greatest potential for significant impact as a pedagogical tool in higher education (Johnson, Smith, Willis, Levine, \& Haywood, 2011). This potential makes these technologies ideal for addressing the current and persistent problems of adequately preparing teachers (Dede, 2009; Johnson et al., 2016), particularly for pre-service special education programs. A body of research on the efficacy of preparing special educators through this platform has been growing over the last decade (e.g., Dieker et al., 2008; Dieker, Lignugaris-Kraft, Hynes, \& Hughes, 2016; Peterson, 2014; Dawson \& Lignugaris/Kraft, 2013; Rock et al., 2016; Walker, 2012; Walker, Vasquez, \& Wienke, 2014) and has yielded similar promising results as research on the use of immersive simulations with preservice teachers in general.

Research exploring the use of immersive simulation has reinforced the growing assertion that experiences devoid of authentic interaction are not an effective means for preparing classroom teachers for real-world experiences (Baumgartner \& Buchanan, 2010; Evans, 2013). As indicated by Straub, Dieker, Hynes, \& Hughes (2014), “[n] ext generation [professional development] environments for teachers to learn both pedagogical and content skills are emerging and computer simulation is at the forefront" (p. 55). Some simulation tools, developed specifically to address the challenges of adequately preparing pre-service teachers, are capable of creating comprehensive educational experiences that are both consistent in exposure to content and responsive to the specific needs and skill sets of the participants (McPherson, Tyler-Wood, McEnturff Ellison, \& Peak, 2011). Special education, in particular, requires professionals to master a set of specialized skills and explicit instructional strategies designed to meet the individualized needs of students with disabilities (McLeskey et al., 2017). Authentic experiences that give pre-service teachers opportunities to practice those approaches consistently and with fidelity are a critical component of teacher preparation in special education (Melnick \& Meister, 2008). As such, immersive simulation as a pedagogical tool has been researched in at least a dozen special education contexts (Dieker et al., 2008). While some studies have been directed at developing special education students' skills (e.g., Dieker, Straub, Hughes, Hynes, \& Hardin, 2014; Walker, 2012), others have been aimed at honing in on targeted behaviors of in-service special education teachers (e.g., Dawson \& Lignugaris/Kraft, 2013; Enicks, 2012; Rodriguez, 2011; Vince-Garland et al., 2012). For example, Myers, Reier, and Lignugaris/Kraft (2010) examined special education teachers' 
accuracy of a specific teaching technique-discrete trial instruction-in an actual classroom before and after training via immersive simulation. The researchers found after just 40 minutes of simulation training, the special education teachers improved from a range of $0-34$ percent accuracy to 100 percent accuracy. Results such as these demonstrate the effectiveness and potential that immersive simulation could have on enhancing special education teacher preparation.

As the use of immersive simulation for special education teacher preparation grows, so do questions about the implementation of immersive technologies as to how to improve practice most effectively. One such question being investigated encompasses the notion of vicarious observational learning during immersive simulations. Initially introduced by Bandura, Ross, \& Ross (1963), vicarious learning is defined as learning that occurs as a function of seeing, retaining, and replicating behavior observed from a model. Moreover, when the model is rewarded for his or her actions, the observer is more likely to replicate the behavior. Since then, understanding of vicarious learning has evolved to suggest that observation promotes imitation of behaviors, even in the absence of reinforcement (Fryling, Johnston, \& Hayes, 2011), thus having implications for vicarious learning through observation of immersive simulations (Hoover et al., 2012). Although immersive simulation is often grounded in situated and experiential learning, there is also evidence of value in vicarious learning paired with experiential learning (Hoover et al., 2012). According to Hoover and colleagues (2012), optimal acquisition of skills in a direct learning experience, such as with immersive simulation, is best met when preceded by complementary vicarious observational learning. Without the opportunity for vicarious observational learning, the learner has the dual task of trying to think about proper execution of a skill while simultaneously focusing on execution of it. By allowing for more cognitive space to process the task prior to execution, the participant is freed from this duality, and skills are honed more quickly than they might have been through direct learning (Hoover et al., 2012) via immersive simulation alone.

According to Hoover (2016), direct experiential learning paired with vicarious observational learning has a considerable amount of promise for reaching adult learners. The potential impact is particularly important for teacher preparation programs when considering the development of skills not readily practiced through coursework alone. In special education, the development of professional collaboration skills is one example. More specifically, developing the skills needed for successful coteaching has become critical to the field (McLeskey et al., 2017). Co-teaching can generally be defined as the partnering of a general education teacher and a special education teacher for the purpose of jointly delivering instruction to a diverse group of students, including those with disabilities, in a general education setting (Friend, 2008; Leko \& Brownell, 2009). As special educators are situated more frequently in co-teaching contexts, the development of these skills is pertinent to their preparation.

With an increased emphasis on educating all students in the least restrictive environment (Individuals with Disabilities Education Improvement Act, 2004), many schools are relying on coteaching as a means for ensuring access to the general curriculum for students with disabilities. However, to be effective, teachers first need to understand the intricacies of co-teaching and co-planning (Friend \& Bursuck, 2002). Often, the burden of effectively enacting co-planning falls to the special education teacher (Friend, Cook, Hurley-Chamberlain, \& Shamberger, 2010; Hudson \& Glomb, 1997). Special educators must be prepared to use their specialized knowledge in the context of co-teaching, but they must also have the professional collaboration skills that are necessary to negotiate roles and responsibilities in the co-taught classroom (Friend \& Cook, 2014). In fact, Scruggs, Mastropieri, and 
McDuffie (2007) argued that without both sets of skills, special education teachers are more likely to become classroom assistants than instructional partners. Both general and special education teachers agree that given the challenges associated with co-planning and co-teaching, more preparation and training is highly critical for success (Leko \& Brownell, 2009; Shin, Lee, \& McKenna, 2016). Given the critical need to develop these skills through teacher preparation and the potential impact of immersive simulation combined with vicarious observational learning, further exploration of whether this approach can be used to teach targeted collaboration skills is warranted.

The purpose of this study was to evaluate the impact of immersive simulation combined with vicarious observational learning within a co-planning scenario. Specifically, pre-service special education majors were asked to demonstrate targeted collaboration skills in three areas: (1) co-planning and coteaching, (2) professional communication, and (3) supports for students with disabilities.

\section{METHOD}

This investigation aimed to answer the following two research questions:

\section{To what extent, if any, does facilitating an immersive co-planning simulation affect targeted collaboration skills among undergraduates in special education?}

\section{To what extent, if any, does vicarious observational learning occur during the immersive co-planning simulation?}

\section{Setting and participants}

The participants included a cohort of pre-service special education majors $(\mathrm{N}=29)$ in the first semester of their senior year at a midsize university in the southeast region of the United States. The program prepares students to teach individuals with mild disabilities in preschool through twelfth grade inclusive settings. Although students have the option of taking an additional certification test that would qualify them to work in resource or self-contained settings after graduating, the focus of the program is preparing them for inclusion settings within a co-teaching model. The study took place in a technology lab in the education center on campus.

The pre-service teachers were taking a course on collaboration in school settings, and they were engaged in the immersive simulation as part of the course requirements. The learning outcomes associated with the course included gaining an understanding of professional roles, responsibilities, and techniques for working collaboratively with others. Those involved in the study were required to participate in the research activities, as it was a component of the class; however, each gave voluntary written consent for their data to be used and disseminated. Given that they were a cohort of undergraduates, at the start of the study they each had a small number of field experiences and none had begun their student teaching internship. It is assumed that most of them had few (if any) opportunities to observe a co-planning session prior to the study and had no experience actually facilitating a coplanning session.

\section{Instrumentation}

To collect data, we used an immersive simulation observation checklist for special education coplanning (ISOC-SEC), an observation tool developed for instructional purposes by lead author Sandra Robbins. A content validation of the ISOC-SEC was conducted through a peer review process before 
the start of the study. Two special education faculty members reviewed the content and provided feedback. As a result, the ISOC-SEC was formatted as a checklist and provided a space for each item in which the peer evaluator was asked to indicate whether or not the co-planning session facilitation group had demonstrated each checklist item during their interaction with the avatar. The checklist items were divided into three sections based on the three learning objectives for the co-planning experience conducted within the immersive environment. Various scholars identify a generally agreed upon set of skills needed for successful co-teaching (see Friend \& Cook, 2014; Ploessi, Rock, Shoenfeld, \& Blanks, 2010; Scruggs et al., 2007), and the three learning objectives were developed with these in mind.

The first session objective for which items were written and included on the ISOC-SEC was that participants will demonstrate an understanding of co-planning and co-teaching techniques. The first objective was deemed a critical learning outcome for special education students due to the legal mandates and societal push for the inclusion of students with disabilities in general education settings (Individuals with Disabilities Education Improvement Act, 2004). Due to this push, and given the context of the accountability era, co-teaching is now a primary role of special education teachers trained in the area of mild disabilities (Friend et al., 2010; Ploessi et al., 2010). Friend, Reising, and Cook (1993) identified five distinct models of co-teaching; however, research has shown that without opportunities to hone this set of knowledge and skills, teachers tend to resort to using one model, whereby the general education teacher is responsible for the class, while the special educator simply provides individualized support for the students with disabilities (Pancsofar \& Petroff, 2016). This first objective (participants will demonstrate an understanding of co-planning and co-teaching techniques) was measured using the following five statements regarding each team:

1. Discussed one or more approaches to co-teaching with the avatar and provided a valid rationale for the use of the suggested approach.

2. Engaged in a back and forth dialogue with the avatar about the expected roles and responsibilities within the co-teaching relationship.

3. Discussed information related to standards, assessments, accommodations/modifications, instructional strategies, and logistics when co-planning the lesson with the avatar.

4. Came to the co-planning session prepared with a meeting agenda to keep everyone on task during the time given.

5. Assumed shared responsibility for the collaborative work and valued the general educator's individual contributions.

The second session objective for which items were written and included on the ISOC-SEC was that participants will utilize professional communication skills. The second objective is particularly important for special educators. Collaborating effectively with family members, general educators, administrators, and related service personnel is a foundational component of special education (McLeskey et al., 2017). Professional communication skills are crucial when conducting meetings about individual education plans, facilitating multifactored evaluations, providing consultation, and navigating the co-teaching relationship (Friend \& Cook, 2014; Ploessi et al., 2010). The sensitive nature of the information being shared and the legal obligation to advocate for students with disabilities means special educators need to be particularly skilled and careful about professional communication. Moreover, research has indicated that practice is essential for the development of communication skills (Ivey, Ivey, \& Zalaquett, 2014). 
The second objective (participants will utilize professional communication skills) was measured using the following six statements regarding the team members:

1. Demonstrated professional verbal communication by expressing ideas clearly and confidently in speech.

2. Demonstrated a willingness to make changes and be flexible throughout the planning process in order to work collaboratively with the avatar.

3. Consistently listened to and acknowledge the feelings, concerns, opinions, and ideas of the avatar.

4. Consistently took the time to acknowledge the avatar's skills, experience, creativity, and contributions.

5. Maintained a positive attitude and expressed all personal opinions and areas of disagreement tactfully.

6. Utilized important communication skills in order to check for agreement and understanding such as asking questions and paraphrasing during back and forth dialogue and summarizing key ideas and agreed upon timelines.

The third session objective for which items were written and included on the ISOC-SEC was that participants will demonstrate knowledge of supports for students with disabilities. The third objective is important because within the co-teaching partnership, and particularly during the co-planning experience, the general education teacher's role is to offer expert understanding of the content, while the special education teacher offers expertise in specialized instruction and supports for meeting the individual needs of students with disabilities (Shaffer \& Thomas-Brown, 2015; Shepherd, Fowler, McCormick, Wilson, \& Morgan, 2016). Special education teachers need to understand their role in the co-teaching partnership and be able to offer real solutions and ideas to build trusting relationships with their general education teacher colleagues (Friend \& Cook, 2014; Youngs, Jones, \& Low, 2011). The third objective was measured using the following nine statements regarding discussions of the team:

1. Used a variety of instructional delivery methods including the use of flexible grouping and small-group instruction.

2. Wide variety of materials, resources, and texts available for student use.

3. Integration of student choice: The teacher provides several assignments that cover a given topic and the students choose the one they want to complete.

4. Possibility of using tiered assignments: Students are instructed on essential skills with assignments across varied levels of complexity.

5. Basic accommodations in place for students such as large print textbooks, adaptive writing utensils, and checklists.

6. Testing and assessment accommodations put in place for students such as additional time, reading tests and directions to students, and highlighting key directions.

7. Presentation accommodations put in place for students such as giving instructions orally, providing students with an outline of the lesson, and providing paper copies of instructions for students.

8. Response accommodations put in place for the students such as dictating answers to a scribe, using a word processor to type notes, and using a calculator or table of math facts. 
9. Organizational skills accommodations put in place for the students such as using an alarm to help with time management, marking texts with a highlighter, and taking sections of a test in a different order.

\section{Procedure}

The pre-service teachers were informed at the start of the semester that one of the assignments for the course would be to work in groups of two or three to engage in their first immersive simulation experience. They were charged with facilitating a conversation with a general education teacher (the adult avatar) to co-plan a science lesson focused on the water cycle. The water cycle was selected as the topic for the lesson for two reasons. First, demonstrating knowledge of the content was not an objective for the activity, so it made sense to select a topic for which most of the participants already had at least a basic level of understanding. Second, the topic of the water cycle lends itself to a variety of options for differentiation of the content, process, and product. The participants were given a sample lesson plan on the water cycle approximately two weeks before the first session.

The pre-service teachers were also given a copy of the ISOC-SEC two weeks prior to the experience. They were informed they would be observing each other during the simulation and evaluating one another (using the ISOC-SEC) on their ability to demonstrate knowledge of (a) coplanning and co-teaching approaches, (b) professional communication, and (c) supports for students with disabilities. At this point in the semester, the participants had already been taught the content associated with each of the objectives and could identify the behaviors outlined in each of the statements on the instrument.

To create a real-world scenario in which the resistance associated with the co-teaching relationship would be felt, the participants were not informed prior to the simulation that the general education teacher (the adult avatar) would be hesitant to make changes to her instruction and that she viewed the special education teacher as somewhat of an intruder in her classroom. In real-world interactions, demonstrating particular skills can elicit certain responses (Ivey, et al., 2014). During the immersive co-planning simulation, the adult avatar had been trained to respond positively and cooperatively when pre-service teachers demonstrated the skills outlined in the ISOC-SECs. If they were unprepared, unprofessional, or did not demonstrate the objectives, the avatar was trained to respond as defensive and inflexible.

As part of the planning for the simulation, the professor pre-taught key information and skills targeted at effective co-planning. Then, two class sessions were dedicated to facilitating co-planning sessions within the immersive environment. Nine groups of participants facilitated a co-planning simulation during the first class session while the other four groups of participants observed; all 13 groups practiced facilitating a co-planning simulation during the second class session two weeks later. The four groups that only observed during session one were randomly placed into that condition. Both the first and second sessions followed the same protocol. Each group had approximately 10 minutes to facilitate the co-planning simulation - a suggested standard in immersive simulation experiences (Dieker et al., 2008). While each small group was engaged in the simulation at the front of the room, the remainder of the pre-service teachers were observing (from the back of the same room) and were tasked with completing the ISOC-SEC while they watched. 
Between each simulation, the professor facilitated brief (approximately two minutes) wholegroup discussions with the class. The focus of each discussion varied based on the perceived strengths and weaknesses of the interaction; however, for each simulation, those who were observing were encouraged to make note of something positive they observed as well as one suggestion for improvement or change. The completed observation checklists were collected at the end of each class session.

\section{Data analysis}

The skill with which each team (two or three students) facilitated the co-planning session was evaluated by their peers via the ISOC-SEC. All members of the class $(\mathrm{N}=29)$ served as independent observers. During each observation, the pre-service teachers placed a checkmark next to an item/statement on the ISOC-SEC if and when they observed any member of the group engaging in that behavior. Each group of two or three students was evaluated as a team. The average number of checkmarks across all observation forms was used to determine each group's overall score as well as a score for each learning objective. For example, each group of two students received scores from 27 independent observers; these scores were then averaged to determine the mean evaluation scores. The participants were not explicitly made aware of the two conditions (participation-participation and observation-participation). Given the small number of groups that participated in this study, practical significance (Cohen's $d$ effect size; Cohen, 1988) was used to evaluate the magnitude of the change in mean peer evaluation scores earned between sessions (Cohen's $d=(M 2-M 1) / S D$ pooled). Our discussion of the results, below, includes descriptive information about the evaluation scores earned by each group of student participants and an evaluation of those data within the context of the research questions posed for the study.

\section{RESULTS}

Groups who participated in facilitating a co-planning session during the first class session (time $1, n=9)$ earned an overall mean evaluation score of $M=10.67(S D=2.15)$. During the second class session (time 2), groups who had also practiced facilitating a co-planning session at time 1 earned an overall mean evaluation score of $M=14.28$ ( $S D=1.91)$, while groups who had observed practice planning sessions at time $1(n=4)$ earned an overall mean evaluation score of $M=15.37(S D=1.05)$. Overall mean evaluation scores had a potential range of 0 to 20; observed overall mean scores ranged from 6.83 to 16.80 . Descriptive statistics for the mean overall evaluation scores as well as the mean score for each of the three session objectives are presented in Table 1.

Table 1. Mean peer evaluation scores by time point for each treatment group ( $n=$ number of groups observed)

\begin{tabular}{lccccc}
\hline TIME AND GROUP & $n$ & OVERALL SCORE & OBJECTIVE 1 & OBJECTIVE 2 & OBJECTIVE 3 \\
\hline $\begin{array}{l}\text { Time 1 } \\
\text { Participation-participation }\end{array}$ & 9 & $\begin{array}{c}10.67 \\
(S D=2.15)\end{array}$ & $\begin{array}{c}3.69 \\
(S D=0.58)\end{array}$ & $\begin{array}{c}4.34 \\
(S D=0.78)\end{array}$ & $\begin{array}{c}2.63 \\
(S D=1.05)\end{array}$ \\
\hline $\begin{array}{l}\text { Time 2 } \\
\text { Participation-participation }\end{array}$ & 9 & $\begin{array}{c}14.28 \\
(S D=1.91)\end{array}$ & $\begin{array}{c}4.44 \\
(S D=0.43)\end{array}$ & $\begin{array}{c}5.68 \\
(S D=0.36)\end{array}$ & $\left.\begin{array}{c}4.16 \\
(S D=1.39\end{array}\right)$
\end{tabular}




\begin{tabular}{lccccc}
\hline Observation-participation & 4 & 15.37 & 4.86 & 5.34 & 4.08 \\
& & $(S D=1.05)$ & $(S D=0.29)$ & $(S D=0.55)$ & $(S D=1.04)$ \\
\hline
\end{tabular}

To answer the first research question - to what extent, if any, does facilitating an immersive coplanning simulation affect targeted collaboration skills among undergraduates in special education-scores earned by the participation-participation groups were compared across the two time points. Given the small number of groups who participated in this study, practical significance (Cohen's $d$ effect size; Cohen, 1988) was used to evaluate the magnitude of the change in mean peer evaluation ratings earned over time. Cohen provides the following guidelines for interpretation of $\mathrm{d}$ as a measure of practical significance: $d<0.20=$ no effect, $0.20<=d<0.50=$ small effect, $0.50<=d<0.80=$ moderate effect, $d$ $>=0.80=$ large effect (Cohen, 1988). The differences in observed mean scores for the overall instrument as well as each subset of items related to each session objective were characterized by very large effect sizes (overall: $M$ change from 10.67 - 14.28, $d=1.78$; objective 1 : $M$ change from 3.69 - 4.44, $d=1.47$; objective 2: $M$ change from $4.34-5.68, d=2.22$; objective $3: M$ change from $2.63-4.16, d=$ 1.24). These results indicate that pre-service teachers did a better job of facilitating a co-planning session after having first practiced doing so during a previous class session.

To answer the second research question - to what extent, if any, does vicarious observational learning occur during the immersive co-planning simulation-scores earned by the observationparticipation groups during their one facilitation practice session at time 2 were compared to the time 2 scores earned by the participation-participation groups. The overall difference between the two treatment groups at time 2 (participation-participation $M=14.28$, observation-participation $M=15.37$ ) was qualified by a moderate effect size, $d=0.71$. The difference between the two groups for session objectives one, two, and three were found to be large $(d=1.15)$, moderate $(d=0.74)$, and small $(d=$ 0.07 ), respectively (descriptive statistics are provided in table 1 ). In all four comparisons, the observation-participation groups earned mean peer evaluation scores higher than those earned by participation-participation groups. These results indicate that vicarious observational learning did in fact occur, and highlight that observing others facilitate an immersive co-planning simulation may be just as effective as having the opportunity to practice for oneself.

\section{DISCUSSION}

When the scores earned by the nine participation-participation groups were compared across sessions one and two, the differences in observed mean scores for the overall instrument was qualified by a very large effect size $(d=1.78)$. This finding shows that when students were given the opportunity to facilitate an immersive co-planning simulation across two class sessions, they performed significantly better the second time around. As Kang (2016) suggests, repetition and practice is critical to honing skills. Our findings suggest the initial session had a positive impact on student learning and highlights the potential value of immersive simulation as a pedagogical tool.

The differences in observed mean scores for each of the three session objectives were also compared across sessions one and two for the nine participation-participation groups. Each of those comparisons also yielded very large effect sizes. For objective one (participants will demonstrate an understanding of co-planning and co-teaching techniques), $d=1.47$; for objective two (participants will utilize professional communication skills), $d=2.22$; and for objective three (participants will demonstrate 
knowledge of supports for students with disabilities), $d=1.24$. These findings show that pre-service teachers in the participant-participant groups made practically significant improvements across each of the session objectives, with the largest improvement in performance seen for objective two (participants will utilize professional communication skills).

The fact that the greatest improvements were observed for objective two was encouraging to us. Carter, Prater, Jackson, and Marchant (2009) suggest that exhibiting professional communication skills is critical to preparing pre-service special education teachers to support inclusion through co-teaching. Objectives one and three both pertained to demonstrating special education content knowledge. While special education content knowledge is an important component of a co-teaching partnership (Adams, 2015), content knowledge has traditionally been obtainable through classroom-based instructional methods such as lecture, reading and discussion. Moreover, it is not likely that limited content knowledge would be immediately detrimental in the beginning stages of a co-teaching partnership. Effective communication skills, on the other hand, are at the very core of developing a successful coteaching relationship (Mastropieri et al., 2005; Murawski, 2012), and may not develop without real or simulated experiences to practice and receive feedback (Ivey et al., 2014; Scruggs et al., 2007). These data suggest that we may have found an effective means to address this critical learning objective for future special education teachers.

The question of whether or not vicarious observational learning occurred during the simulation was explored by comparing the scores earned by the nine participation-participation groups during session two with the scores earned by the four observation-participation groups. The overall difference between the two treatment groups during session two was qualified by a moderate effect size $(d=0.71)$. In other words, the four observation-participation groups earned mean scores higher than those earned by the nine participation-participation groups during session two. This result indicates that vicarious observational learning likely occurred during the first session and alludes to the idea that observing others facilitate an immersive co-planning simulation may be just as effective as having the opportunity to practice for oneself. This finding indicates that targeted collaboration skills can be learned vicariously. Further exploration of this idea may lead to important changes in how teacher preparation programs in special education engage candidates in learning.

To further explore the difference between the two treatment groups, mean scores were compared across each of the three session objectives. While the observation-participation group outperformed the participation-participation group with regard to the ISOC-SEC's objective one (participants will demonstrate an understanding of co-planning and co-teaching techniques) at time two (large effect size, $d=1.14$ ), the participation-participation group outperformed the observationparticipation group at time two with regard to objective two (participants will utilize professional communication skills; moderate effect size, $d=0.74$ ). No difference was identified between the two groups at time two for objective three as measured by the ISOC-SEC. Together, these results may indicate a notable difference between the observation-participation group and the participation-participation group: each group demonstrated their highest level of performance on a different set of targeted skills. That is, those who participated at time one demonstrated better professional communication at time two; and those who observed at time one demonstrated better co-teaching knowledge at time two. The difference between the groups could be attributed to differences in scoring behaviors from time one to time two, or it could have implications for practice. 


\section{Limitations}

There are a number of limitations to take into consideration when interpreting the results of this investigation. First, there was a small number of participants, and they were exposed to the intervention for only a short window of time. In addition, they were given the instrument prior to the experience and had time to plan collaboratively before the session. During the session, there was whole-group dialogue between each simulation designed to guide their thinking and build upon teachable moments; however, we contend this is good pedagogy. Given a lack of a control condition or alternative treatment, it is difficult to discern whether the immersive co-planning simulation or one of these other variables led to the significant results of the investigation.

The significance of the results should also be interpreted with caution because of the instrument utilized by the participants. Although the ISOC-SEC was developed for the purpose of the study and vetted by professionals in the field, the reliability of the tool has not been established. The participants were familiar with the content of the observation tool, but the information was new to them and they were not formally trained to score each item with reliability. Moreover, having used the instrument twice, practice effects must be considered. That is, the participants may have gained proficiency from time one to time two simply because they had already been exposed to it once before. It is also possible that as the semester progressed, students developed a more supportive relationship with one another that may have affected how they rated one another the second time around. Another consideration is that while the students were not made explicitly aware of the two conditions (participationparticipation, observation-participation), it is possible that some or all of them picked up on this nuance during the second session, leading them to score their peers who were participating in the simulation for the first time differently than they scored their peers who were participating for the second time around.

The limitations of the study must be taken into consideration when interpreting the results and caution should be used when making broad generalizations about the effects of the immersive simulation. No data were collected regarding the transfer of these targeted collaboration skills into realworld settings as part of this investigation; however, several other researchers (e.g., Straub et al., 2014; Miller et al., 2014; Myers et al., 2010) have found that skills obtained via immersive simulation are both generalized and maintained over time.

\section{Implications}

Immersive simulation is still in the nascent stages of use in teacher preparation, but as Dieker, Rodriguez, Lignugaris/Kraft, Hynes, Hughes (2016) and a growing body of literature (Chini et al., 2016) suggest, there is increasing evidence to support its potential to evolve into a powerful pedagogical tool for preparing teachers. The results of this study lend to the expansion of this body of evidence by demonstrating that (a) targeted collaboration skills can be improved through the opportunity to observe and participate in immersive simulation, and (b) for pre-service teachers who participated more than once, the simulation had a more powerful impact on professional communication skills than anything else-skills that are not likely to develop without real or simulated opportunities to practice and hone (Ivey et al., 2014; Scruggs et al., 2007). A general implication of the results may be that as professors of teacher preparation programs, we should consider using immersive simulation to enhance courses that involve the development of skills that require practice-based preparation. Given the increasing need for 
these kinds of experiences in teacher education (Council for the Accreditation of Educator Preparation, 2013; National Council for Accreditation of Teacher Education, 2010), immersive simulation holds great promise for teacher preparation programs. We see this tool as a potential buoy to the pressures associated with the accountability era in which we are situated.

The results of this investigation have also indicated that vicarious observational learning had a positive impact on student learning outcomes. This finding is supported by previous research demonstrating the potential for vicarious observational learning to affect adult learning (Hoover, 2016; Hoover et al., 2012). In this investigation, not only did students who observed during the first session perform well during the second session, but they performed better overall than did their peers who participated in the simulation during session one. As Hoover and her colleagues indicated, cognitive space is created when learners are freed from the duality of simultaneously processing and executing new skills when vicarious observational learning is incorporated into learning. Based on these findings, teacher preparation programs interested in utilizing immersive simulation as a pedagogical tool may want to consider incorporating vicarious observational learning into those experiences. For some programs, it may be deemed too expensive or time consuming to offer immersive simulation experiences to large numbers of students. In those cases, finding that groups of students can simply observe these sessions and still achieve important learning outcomes may allow for increased use of immersive simulation as a pedagogical tool. Additionally, a turn-taking strategy could be implemented so that students have the opportunity to both participate in and observe the immersive simulations. We suspect this finding could suggest an opportunity to reimagine teaching and learning in a new era, where immersive simulation and vicarious observational learning are relied upon for scaffolded and targeted learning outcomes.

Finally, because the two groups appear to have made the greatest gains among two different sets of skills from the experience (those who participated at time 1 demonstrated better professional communication at time 2; and those who observed at time 1 demonstrated better co-teaching knowledge at time 2), the difference between the groups could implicate a need to vary the procedures for immersive simulation depending on the intended learning outcome. For example, when a targeted learning outcome is content related, such as knowledge of teaching strategies or approaches, affording students the opportunity to experience vicarious observational learning during immersive simulation may be the best approach. On the other hand, if the targeted learning outcome is to improve upon skills that require practice-based experiences to develop, such as communication or relationship-building skills, providing students with an opportunity to facilitate an immersive simulation experience may be more effective than to providing an opportunity to observe one. This finding may warrant additional research that examines the impact of vicarious observational learning during immersive simulation on different learning outcomes.

\section{Future directions}

Overall, it appears the effects of immersive simulation on targeted co-planning skills of special education students are of practical significance. The students who facilitated the session the first time around performed significantly better in all areas the second time around.

Moreover, the students who observed the first time around outperformed the group that facilitated the first time around. Replicating this study with a larger sample size would provide more 
definitive information on questions yet to be answered. Including a control or alternate treatment group would also provide more reliable results. Notably, further exploration of whether observing a session and facilitating a session result in different types of learning is warranted. Replicating this finding with more rigor could lead to powerful implications for teacher preparation programs. If participating in immersive simulation is a powerful way to improve targeted collaboration skills among teacher candidates, perhaps other skills that are strong predictors of student success, such as relationship building, fostering motivation and engagement (Klem \& Connell, 2009), and providing effective instructional feedback (Thurlings, Vermeulen, Bastiaens, \& Stijnen, 2013), can be cultivated using this approach.

Future research may also be warranted to answer questions not directly addressed in this study. For example, would the students who observed the first time around perform as well if they did not have as much time to prepare, or if they did not know they were going to have to facilitate a session the second time around? Also, given that many institutions are shifting from face-to-face instruction to online courses, location may be another variable worth exploring. Would the immersive co-planning simulation have the same level of impact if the students observing the session were not in the same room as the individuals facilitating the session? Thus, focus areas for ongoing research might include (a) the best ways to engage students during observations and (b) whether vicarious observational learning during immersive simulation is something that can be effectively used via distance technology.

Finally, given the time commitment and costs associated with the use of immersive technology, it is important that researchers carefully examine the added value of it as a pedagogical tool. It is becoming clear that immersive simulation can have a powerful impact on student learning, but is it more powerful than more traditional and less expensive methods of teaching? For example, does immersive simulation have a greater impact on student learning than engaging in a role play scenario? Ongoing research in this area will expand our thinking about the effects of immersive technology, the presence, impact, and possibilities of vicarious observational learning, and how we can most efficiently use various innovative and promising pedagogical tools to better prepare pre-service special education teachers for success in the 21 st century.

Sandra H. Robbins is an Associate Professor of Special Education at the University of West Georgia (USA). Her scholarship focuses on interventions for young children with and at risk for disabilities and approaches to personnel preparation in early childhood special education.

Kristen Gilbert is an Assistant Professor of Educational Leadership at Augusta University (USE). Her scholarly work focuses on restorative justice and leadership practices that promote equity for all children.

Frances Chumney earned a PhD in Quantitative, Qualitative, and Psychometric Methods with a doctoral minor in Survey Research Methods from the University of Nebraska-Lincoln. Since 2018, she has served as Senior Researcher for Psychometric Methods for The Marcus Buckingham Company and the ADP Research Institute (USA).

Katherine Green is an Associate Professor and Program Coordinator of Special Education at the University of West Georgia (USA). Her passion and expertise include teacher education and innovations, social-emotional, early communication, and academic supports for young children with disabilities and their families. 


\section{NOTES}

1. Dr. Sandra Robbins and Dr. Kristen Gilbert, the first two authors of this manuscript, sadly left us far too soon. Both Drs. Robbins and Gilbert were experts in innovative methods in teacher education, and had a passion for the Scholarship of Teaching and Learning. They are greatly missed among family, friends, and colleagues. We will always remember them for their contributions to our field. We hope this manuscript will serve as a tribute to them both. Due to these circumstances, please send any correspondence regarding this manuscript to Dr. Katherine Green.

\section{REFERENCES}

Adams, Stacy M. (2015). Co-teaching using the Common Core state standards in a secondary mathematics classroom (Unpublished master's theses). College at Brockport, Brockport, New York.

Allsopp, D. H., DeMarie, D., Alvarez-McHatton, P., \& Doone, E. (2006). Bridging the gap between theory and practice: Connecting courses with field experiences. Teacher Education Quarterly, 33(1), 19-35. Retrieved from http://www.teqjournal.org/backvols/2006/33 1/07allsoppetal.pdf

Bandura, A., Ross, D., \& Ross S. A. (1963). Vicarious reinforcement and imitative learning. Journal of Abnormal and Social Psychology, 67(6), 601-607.

Baumgartner, J. J., \& Buchanan, T. K. (2010). "I have HUGE stereo-types": Using eco-maps to understand children and families. Journal of Early Childhood Teacher Education, 31(2), 173-184. https://doi.org/10.1080/10901021003781270

Brownell, M. T., Ross, D. D., Colón, E. P., \& McCallum, C. L. (2005). Critical features of special education teacher preparation: A comparison with general teacher education. Journal of Special Education, 38(4), 242-252. https://doi.org/10.1177/00224669050380040601

Carter, N., Prater, M., Jackson, A., \& Marchant, M. (2009). Educators' perceptions of collaborative planning processes for students with disabilities. Preventing School Failure, 54(1), 60-70. https://doi.org/10.3200/PSFL.54.1.60-70

Chini, J. J., Straub, C. L., \& Thomas, K. H. (2016). Learning from avatars: Learning assistants practice physics pedagogy in a classroom simulator. Physical Review Physics Education Research, 12(1), 010117. https://doi.org/10.1103/PhysRevPhysEducRes.12.010117

Cohen, J. (1988). Statistical power analysis for the behavioral sciences (2nd ed.). Hillsdale, NJ: Lawrence Earlbaum Associates.

Council for the Accreditation of Educator Preparation. (2013). CAEP accreditation standards and evidence: Aspirations for educator preparation. Retrieved from http://caepnet.org/ /media/Files/caep/standards/commrpt.pdf?la=en

Darling-Hammond, L., Meyerson, D. L., LaPointe, M., Orr. M. T. (2010). Preparing school leaders for a changing world: Lessons from effective school leadership programs. San Francisco, CA: Jossey Bass.

Dawson, M., \& Lignugaris/Kraft, B. (2013). TLE TeachLivE ${ }^{\mathrm{TM}}$ vs. role-play: Comparative effects on special educators' acquisition of basic teaching skills. In A. Hayes, S. Hardin, L. Dieker, C. Hughes, M. Hynes, \& C. Straub (Eds.), Proceedings from the 1st National TLE Teach LivE ${ }^{T M}$ Conference (pp. 23-29). Retrieved from http://teachlive.org/wpcontent/uploads/2014/05/2013\%20TLE TeachLivEProceedings FINAL 9 20.pdf

Dawson, M. R., \& Lignugaris/Kraft, B. (2016). Meaningful practice: Generalizing foundation teaching skills from TLE TeachLivE ${ }^{\mathrm{TM}}$ to the classroom. Teacher Education and Special Education, 40(1), 26-50. https://doi.org/10.1177/0888406416664184

Dede, C. (2009). Immersive interfaces for engagement and learning. Science, 323(5910), 66-69. https://doi.org/10.1126/science.1167311

Dieker, L., Hynes, M., Hughes, C., \& Smith, E. (2008). Implications of mixed reality and simulation technologies on special education and teacher preparation. Focus on Exceptional Children, 40(6), 1-20. Retrieved from https://journals.ku.edu/focusXchild/article/view/6877/6227

Dieker, L. A., Lignugaris/Kraft, B., Hynes, M., \& Hughes, C. E. (2016). Mixed reality environments in teacher education: Development and future applications. In B. L. Ludlow \& B. C. Collins (Eds.), Online in real time: Using Web 2.0 for distance education in rural special education (pp. 116-125). 
Morgantown, WV: American Council for Rural Special Education. Retrieved from https://www.acres-sped.org/files/d/608dc29d-9bfe42e9bf1912c0bc4642dd/acresmonograph 2016.pdf

Dieker, L. A., Rodriguez, J.A., Lignugaris/Kraft, B., Hynes, M., \& Hughes, C.E. (2014). The potential of simulated environments in teacher education: Current and future possibilities. Teacher Education and Special Education, 37(1), 21-33 https://doi.org/10.1177/0888406413512683

Dieker, L. A., Straub, C. L., Hughes, C. E., Hynes, M. C., \& Hardin, S. (2014). Learning from virtual students. Educational Leadership, 71(8), 54-58. Retrieved from http://www.ascd.org/publications/educational-leadership/may14/vol71/num08/Learning-fromVirtual-Students.aspx

Enicks, A. (2012). Using TeachLive ${ }^{\mathrm{TM}}$ to improve pre-service special education teacher practices (Unpublished doctoral dissertation). Western Michigan University, Kalamazoo, Michigan.

Evans, R. (2013). Educating preservice teachers for family, school, and community engagement. Teaching Education, 24(2), 123-33. https://doi.org/10.1080/10476210.2013.786897

Friend, M. (2008). Co-teach! A manual for creating and sustaining classroom partnerships in inclusive schools. Greensboro, NC: Marilyn Friend.

Friend, M., \& Bursuck, W. D. (2002). Including students with special needs: A practical guide for classroom teachers (3rd ed.). Boston, MA: Allyn \& Bacon.

Friend, M., \& Cook, L. (2014). Interactions: Collaboration skills for school professionals (8th ed.). Boston, MA: Pearson.

Friend, M., Cook, L., Hurley-Chamberlain, D., \& Shamberger, C. (2010). Co-teaching: An illustration of the complexity of collaboration in special education. Journal of Educational and Psychological Consultation, 20(1), 9-27. https://doi.org/10.1080/10474410903535380

Friend, M., Reising, M., \& Cook, L. (1993). Co-teaching: An overview of the past, a glimpse at the present, and considerations for the future. Preventing School Failure: Alternative Education for Children and Youth, 37(4), 6-10. https://doi.org/10.1080/1045988X.1993.9944611

Fryling, M. J., Johnston, C., \& Hayes, L. J. (2011). Understanding observational learning: An interbehavioral approach. The Analysis of verbal behavior, 27(1), 191-203. https://doi.org/10.1007/BF03393102

Gilbert, K. A. (2017). Innovative leadership preparation: Enhancing legal literacy to create 21st century ready principals. Academy of Educational Leadership Journal, 21(1), 127-169. Retrieved from https://www.abacademies.org/articles/innovative-leadership-preparation-enhancing-legal-literacyto-create-21st-century-ready-principals-6774.html

Hoover, J. D. (2016). Vicarious observational learning through visual media: The 12 Angry Men film as an organizational behavior primer. Developments in Business Simulation and Experiential Learning, 43, 266271. Retrieved from https://journals.tdl.org/absel/index.php/absel/article/view/3046/2994

Hoover, J. D., Giambatista, R. C., \& Belkin, L. Y. (2012). Eyes on, hands on: Vicarious observational learning as an enhancement of direct experience. Academy of Management Learning \& Education, 11(4), 591-608. https://doi.org/10.5465/amle.2010.0102

Hudson, P., \& Glomb, N. (1997). If it takes two to tango, then why not teach both partners to dance? Collaboration instruction for all educators. Journal of Learning Disabilities, 30(4), 442-448. https://doi.org/10.1177/002221949703000411

Individuals with Disabilities Education Improvement Act (2004). P. L. 108-446, 118 Stat. 2647.

Ivey, A. E., Ivey, M. B., \& Zalaquett, C. P. (2014). Intentional interviewing and counseling: Facilitating client (8th ed). Belmont, CA: Brooks/Cole.

Johnson, L., Adams Becker, S., Cummins, M., Estrada, V., Freeman, A., \& Hall, C. (2016). NMC Horizon Report: 2016 Higher Education Edition. Austin, TX: The New Media Consortium. Retrieved from http://cdn.nmc.org/media/2016-nmc-horizon-report-he-EN.pdf

Johnson, L., Smith, R., Willis, H., Levine, A., \& Haywood, K. (2011). The Horizon Report: 2011 Edition. Austin, TX: The New Media Consortium. Retrieved from https://files.eric.ed.gov/fulltext/ED515956.pdf

Kang, S. H. K. (2016). Spaced repetition promotes efficient and effective learning: Policy implications for instruction. Policy Insights from the Behavioral and Brain Sciences, 3(1), 12-19. https://doi.org/10.1177/2372732215624708 
Klem, A. M., \& Connell, J. P. (2009). Relationships matter: Linking teacher support to student engagement and achievement. Journal of School Health, 74(7), 262-273. https://doi.org/10.1111/j.17461561.2004.tb08283.x

Leko, M. M., \& Brownell, M. T. (2009). Crafting quality professional development for special educators: What school leaders should know. Teaching Exceptional Children, 42(1), 64-70. https://doi.org/10.1177/004005990904200106

Mastropieri, M. A., Scruggs, T. E., Graetz, J., Norland, J., Gardizi, W., \& McDuffie, K. (2005). Case studies in coteaching in the content areas: Successes, failures, and challenges. Intervention in School and Clinic, 40(5), 260-270. https://doi.org/10.1177/10534512050400050201

McLeskey, J., Barringer, M. D., Billingsley, B., Brownell, M., Jackson, D., Kennedy, M., . . \& Winn, J. (2017). Highleverage practices in special education. Arlington, VA: Council for Exceptional Chidren \& CEEDAR Center.

McPherson, R., Tyler-Wood, T., McEnturff Ellison, A., \& Peak, P. (2011). Using a computerized classroom simulation to prepare pre-service teachers. Journal of Technology and Teacher Education, 19(1), 93-110.

Melnick, S. A., \& Meister, D. G. (2008). A comparison of beginning and experienced teachers' concerns. Educational Research Quarterly, 31(3), 39-56.

Miller, J. L., Rambeck, J.H., Snyder, A. (2014). Improving emergency preparedness system readiness through simulation and interprofessional education. Public Health Reports, 129(6), 129-135. https://doi.org/10.1177/00333549141296S417

Murawski, W. W. (2012). 10 tips for using co-planning time more efficiently. Teaching Exceptional Children, 44(4), 8-15. https://doi.org/10.1177/004005991204400401

Myers, C., Reier, S., \& Lignugaris/Kraft, B. (2010, November). The use of practice in a virtual classroom to improve fidelity of implementation of discrete trial teaching in public school classrooms. Paper presented at the Annual Meeting of the Teacher Education Division of the Council for Exceptional Children: St. Louis, MO.

National Council for Accreditation of Teacher Education. (2010). Transforming teacher education through clinical practice: A national strategy to prepare effective teachers. Washington, DC: National Council for Accreditation of Teacher Education. Retrieved from https://files.eric.ed.gov/fulltext/ED512807.pdf

Pancsofar, N., \& Petroff, J. G. (2016). Teachers' experiences with co-teaching as a model for inclusive education. International Journal of Inclusive Education, 20(10), 1043-1053. https://doi.org/10.1080/13603116.2016.1145264

Peters, M. A., \& Araya, D. (2011). Transforming American education: Learning powered by technology. E-Learning and Digital Media, 8(2), 102-181. https://doi.org/10.2304/elea.2011.8.2.102

Peterson, M. B. (2014). Pre-service special education teachers' frequency of opportunities to respond in the TeachLivE ${ }^{\mathrm{TM}}$ virtual classroom (Unpublished doctoral dissertation). Texas Women's University, Denton, Texas.

Ploessi, D., Rock, M., Schoenfeld, N., \& Blanks, B. (2010). On the same page: Practical techniques to enhance coteaching interactions. Intervention in School and Clinic, 45(3), 158-168. http://dx.doi.org/10.1177/1053451209349529

Robbins, C., \& Searby, L. (2013). Exploring parental involvement strategies utilized by middle school interdisciplinary teams. School Community Journal, 23(2), 113-136. Retrieved from https://files.eric.ed.gov/fulltext/EJ1028844.pdf

Rock, M. L., Spooner, F., Nagro, S., Vasquez, E., Dunn, C., Leko, M., .. Jones, J. L. (2016). 21st century change drivers: Considerations for constructing transformative models of special education teacher development. Teacher Education and Special Education, 39(2), 98-120. https://doi.org/10.1177/0888406416640634

Rodriguez, J. (2011, November). Comparison of feedback methods for pre-service teachers delivering mathematics lessons in the TeachME Lab. Paper presented at the Teacher Education Division of the Council for Exceptional Children, Austin, TX.

Scruggs, T. E., Mastropieri, M. A., \& McDuffie, K. A. (2007). Co-teaching in inclusive classrooms: A metasynthesis of qualitative research. Exceptional Children, 73(4), 392-416. https://doi.org/10.1177/001440290707300401 
Shaffer, L., \& Thomas-Brown, K. (2015). Enhancing teacher competency through co-teaching and embedded professional development. Journal of Education and Training Studies, 3(3), 117-125. http://dx.doi.org/10.11114/jets.v3i3.685

Shepherd, K. G., Fowler, S., McCormick, J., Wilson, C. L., \& Morgan, D. (2016). The search for role clarity: Challenges and implications for special education teacher preparation. Teacher Education and Special Education, 39(2), 83-97. https://doi.org/10.1177/0888406416637904

Shin, M., Lee, H., \& McKenna, J. W. (2016). Special education and general education preservice teachers' coteaching experiences: A comparative synthesis of qualitative research. International Journal of Inclusive Education, 20(1), 91-107. https://doi.org/10.1080/13603116.2015.1074732

Straub, C., Dieker, L., Hynes, M., \& Hughes, C. (2014). 2014 TeachLive National Research Findings: Year 1 findings. Using virtual rehearsal in TLE TeachLivE ${ }^{\mathrm{TM}}$ mixed reality classroom simulator to determine the effects on the performance of mathematics teachers. In C. Straub, L. Dieker, M. Hynes, \& C. Hughes (Eds.), Proceedings of the Ludic Convergence: The Second National TLE Teach LivE ${ }^{\mathrm{TM}}$ Conference (pp. 51-98). Retrieved from http://teachlive.org/wp-content/uploads/2014/12/2014-Teachlive-ConferenceProceedings.pdf

Thurlings, M., Vermeulen, M., Bastiaens, T., \& Stijnen, S. (2013). Understanding feedback: A learning theory perspective. Educational Research Review, 9, 1-15. https://doi.org/10.1016/j.edurev.2012.11.004

Vince-Garland, K., Vasquez, E., III, \& Pearl, C. (2012). Efficacy of individualized coaching in a virtual reality classroom for increasing teachers' fidelity of implementation of discrete trial teaching. Education and Training in Autism and Developmental Disabilities, 47(4), 502-515.

Walker, Z. (2012). Providing coaching on employability skills for students with intellectual disabilities in a virtual environment (Unpublished doctoral dissertation). University of Central Florida, Orlando, Florida.

Walker, Z., Vasquez, E., \& Wienke, W. (2014). Job interview coaching in a virtual environment for individuals with intellectual disabilities. In C. Straub, L. Dieker, M. Hynes, \& C. Hughes (Eds.), Proceedings of the Ludic Convergence: The Second National TLE TeachLivE ${ }^{\mathrm{TM}}$ Conference (pp. 45-48). Retrieved from http://teachlive.org/wp-content/uploads/2014/12/2014-Teachlive-Conference-Proceedings.pdf

Youngs, P., Jones, N., \& Low, M. (2011). How beginning special and general education elementary teachers negotiate role expectations and access professional resources. Teachers College Record, 113, 1506-1540.

Copyright for the content of articles published in Teaching \& Learning Inquiry resides with the authors, and copyright for the publication layout resides with the journal. These copyright holders have agreed that this article should be available on open access under a Creative Commons Attribution License 4.0 International (https://creativecommons.org/licenses/by/4.0). The only constraint on reproduction and distribution, and the only role for copyright in this domain, should be to give authors control over the integrity of their work and the right to be properly acknowledged and cited, and to cite Teaching \& Learning Inquiry as the original place of publication. Readers are free to share these materials - as long as appropriate credit is given, a link to the license is provided, and any changes are indicated. 